\title{
Public Engagement in Ontario's Hospitals - Opportunities and Challenges
}

Karen Born and Andreas Laupacis

\begin{abstract}
The Excellent Care for All Act strengthens the accountability of healthcare provider organizations to the public. However, the ways in which healthcare organizations have engaged the public have often been limited. There are a number of organizations and approaches described in this paper that have exceeded existing public governance and input processes by involving, engaging and partnering with the public. Their processes range from engaging with patients to improve the quality, safety and appropriateness of healthcare services to approaches that strengthen organizational decision making and strategic planning.
\end{abstract}

\section{The Argument for Public Engagement}

Hospitals in Ontario are facing difficult choices about setting priorities, allocating resources and providing quality services. One approach that Ontario hospitals could draw on to help improve the quality and legitimacy of their choices is by engaging the public in decision making. While experts and stakeholders within the healthcare system provide crucial technical expertise, citizens provide expertise in "lived experience" that is complementary to the experts' input (Maxwell et al. 2003).

Public engagement is especially warranted within Canada's publicly funded healthcare system for at least four reasons (Bruni et al. 2008). First, as the public are both the main funders and users of the healthcare system, they are the most important stakeholders. Second, the public should be at the table when decisions are made, in keeping with democratic principles (Maioni 2010). Third, it has been argued that public involvement in decision making provides important insights into what members of the public value. These insights should lead to higher-quality decisions, or at least to greater acceptance of decisions made with citizen input. Finally, empowering the public to provide input into the healthcare system helps improve public trust and confidence (Bruni et al. 2008).

Healthcare organizations can engage members of the public through a variety of approaches and for many purposes. Health Canada (2000) adapted a Public Involvement Continuum framework to capture the range of purposes and the depth to which the public can be informed, involved and engaged by healthcare organizations (see Figure 1).

Governments and health regions in Canada have increasingly adopted public engagement processes along this continuum, developing deliberative processes and councils to inform policy questions and commissions (Mitton et al. 2009). For example, the 2002 Romanow Commission included extensive engagement with the public and key healthcare stakeholders. However, it is our observation that hospitals have focused the majority of their engagement efforts on the communications, education and information-gathering end of the spectrum mostly on one-way communication to inform and educate the public and patients. They tend to have few mechanisms for involving the public in decision-making processes.

While hospitals formally engage citizens through public boards of directors, these individuals are generally selected for their stature in the community, their governance expertise and their fundraising abilities (Bruni et al. 2008). Although hospital boards provide an important link to the community, research suggests that the demographic and socioeconomic characteristics found in hospital boards of governors do not mirror those of the general public (Frankish et al. 2002). These individuals may not 
FIGURE 1.

Health Canada's public involvement continuum

Level 1

Low level of public involvement and influence

Inform or Educate
Level 2

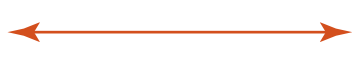

Gather Information
Level 3

Mid level of public involvement and influence

Discuss
Level 4

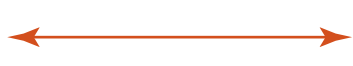

Engage
Level 5

High level of public involvement and influence

Partner

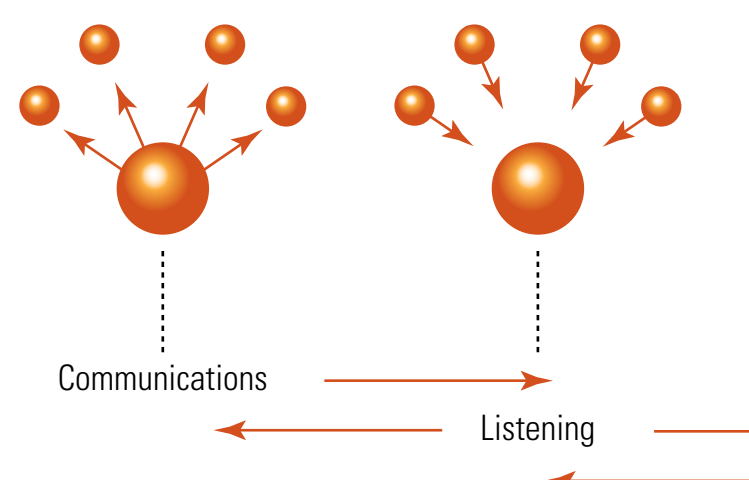

Adapted from Patterson Kirk Wallace as cited in Health Canada 2000
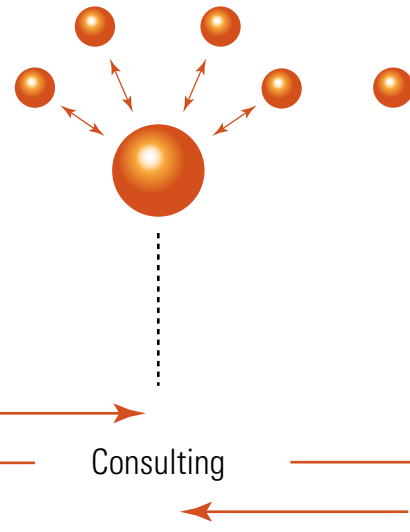
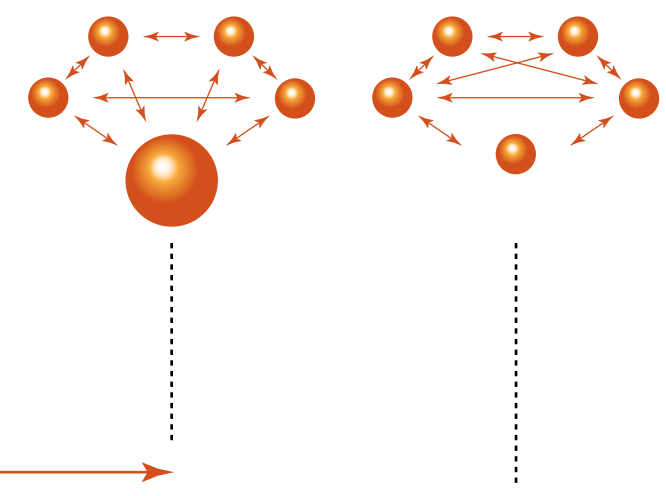

Engaging

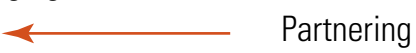

appreciate the healthcare issues faced by the different sectors of the community that their hospitals serve (Chessie 2009).

\section{... the ECFA Act creates legislative mechanisms that strengthen the role of hospital governors and their ability to improve public responsiveness and accountability.}

In addition to having members of the public sit on hospital boards, most Ontario hospitals have at least some mechanisms in place to receive citizen input. At a minimum, they include feedback from regular patient satisfaction surveys and from a hospital ombudsperson who can respond to patient concerns and complaints. However, these approaches are similarly focused on information gathering, listening and communication. Hospitals can strengthen decision-making processes by moving further along the spectrum by consulting, engaging and partnering with patients, communities and the public.

\section{Excellent Care for All and Mechanisms for Public Engagement}

More intensive public engagement approaches can improve existing mechanisms for quality improvement and engagement. The Excellent Care for All Act (ECFA Act) (Legislative Assembly of Ontario 2010) introduces a number of these mechanisms. In its preamble, the ECFA Act states that:

\section{The people of Ontario and their government are committed to ensuring that healthcare organizations are responsive and accountable to the public, and focused on creating positive patient experience and delivering high quality healthcare. \\ (Legislative Assembly of Ontario 2010)}

Beyond affirming the value of a patient-centred healthcare system, the ECFA Act creates legislative mechanisms that strengthen the role of hospital governors and their ability to improve public responsiveness and accountability.

Citizen engagement processes can help build public trust, improve accountability and provide insights around quality. They can inform complex decision-making processes and help develop programs and services that are responsive to public 
needs. But considerations of context are essential. Research suggests that organizations should pay careful attention to the context of the issues they are seeking public engagement and input for (Abelson et al. 2007). Understanding the context informs approaches and helps select individuals well suited to the public engagement processes. The Canadian Institutes of Health Research (2010) framework for citizen engagement includes a typology of citizens to reflect the various publics, such as patients, the general public and organized community groups.

Context determined the approach to addressing a specific question about a single issue at the Northumberland Hills Hospital - how to deal with an impending hospital deficit. Consequently, the hospital convened a Citizen Advisory Panel to conduct a deliberative, time-limited approach with members of the general public. Kingston General Hospital's Patient and Family Advisory Council and the St. Michael's Hospital Community Advisory Panels illustrate a different approach. These advisory bodies include members of the hospitals' patient communities and are integrated into the organizations in a formalized partnership capacity.

In these examples, Ontario organizations have consulted, engaged and partnered with members of the public to strengthen organizational decision making, improve quality and safety and inform strategic planning processes. In the following section, we describe them in more detail.

\section{Public Involvement: Northumberland Hills Hospital Citizens Advisory Panel}

After running three successive years of operating deficits, the Northumberland Hills Hospital, located in Cobourg, Ontario, initiated a Community Advisory Panel (CAP) process that engaged a representative sample of 28 members of the public over a three-month period. The process was motivated by the imperative to bring the hospital's deficit under control, which would necessitate difficult decisions about the services the hospital provided. The hospital did not take this decision lightly, knowing that shifting or removing services would impact patients, hospital staff and the wider community.

Members of the public were invited to participate in the CAP through a civic lottery process, where 5,000 random households in the community were mailed an invitation. The 28 community members selected were balanced for gender, age and geography. The CAP was tasked with providing the hospital board with recommendations around which of the 23 core service areas could be cut and shifted to the community, in order to balance the budget. CAP members developed six criteria to help prioritize the hospital's services according to values determined by the group. Along with criteria such as sustainability and accessibility, they included effectiveness, safety and high standards that focused on quality, safety, patient outcomes and best practices. The recommendations, along with input from hospital staff, physicians and senior leaders, were taken into consideration during the board's decision-making process, and the board's decisions largely aligned with the citizens' recommendations (Northumberland Hills Hospital 2010).

This approach reflects the Health Canada (2000) public involvement continuum of discussion and consulting, as this was a specific issue where the community would be affected by the outcome. As such, a process that facilitated public involvement and discussion, as well as an opportunity to influence the final outcome, was appropriate. The process not only supplied legitimacy to a difficult process, it also helped build public trust in hospital decision makers (The Monieson Centre, Queen's School of Business 2010).

Northumberland Hills Hospital's CAP is the first participatory hospital budgeting exercise in Canada that we are aware of. However, Ontario and the Northumberland Hills Hospital are not alone in facing these challenges. Other jurisdictions are grappling with similar issues - the United Kingdom's National Health Service, for example, is facing political pressure to reconfigure hospital services (Cole 2011). However, the UK-based Kings Fund warns in a 2010 policy briefing against blunt political decisions, suggesting that "ways need to be found to de-politicize the process and to make decisions on the basis of quality, safety and efficiency, while retaining strong citizen engagement in local decision-making" (Imison 2011: 1). The briefing emphasizes that public involvement should occur when there are credible choices and options for the public to review.

\section{... engaging patients directly can provide more in-depth advice, insight and clarity on how to address concerns around the quality of patient care.}

\section{Patient and Family Engagement: Kingston General Hospital Patient and Family Advisory Council}

In Ontario, some hospitals have developed structures for ongoing engagement of patients and the public within the organization. One such example is the Kingston General Hospital Patient and Family Advisory Council, founded in February 2010 as part of a broader organizational strategy of improving patient and family-centred care (Kingston General Hospital 2010). The Patient and Family Advisory Council is composed of patients, family members and hospital staff, including the vice president of clinical administration, professional practice, and the chief nursing executive. Council members are distributed among hospital core program areas of medicine, emergency, surgery, oncology, mental health and pediatrics. Among the council's 
responsibilities are identifying opportunities for improvement around quality of care and patients' experiences.

Ongoing patient and family input into hospital programs goes beyond a time-limited discussion and toward engagement along the Health Canada (2000) public involvement continuum, where there is an opportunity for the public to shape the agenda. The engagement is characterized by an open time frame for deliberation around the issues that are important to patients and their families, and where options generated through engagement will be respected. For example, the Patient and Family Advisory Council recommended increasing the visibility of hand hygiene compliance rates through the organization and requested that handwashing rates be posted at hospital entrances, as well as on individual patient units. (D. Bell, manager of PAC, Kingston General Hospital, personal communication February 27, 2012)

Patient satisfaction surveys can also benefit from engagement with patient, family and community councils. It has been argued that satisfaction surveys are an insufficient basis for identifying areas for improvement (Martin and Ronson 2007). While hospitals are mandated to collect surveys about quality of care and patient experiences, there are well known limitations around the sensitivity, specificity and depth of these surveys. Given these limitations, engaging patients directly can provide more in-depth advice, insight and clarity on how to address concerns around the quality of patient care.

\section{Community Partnership: St. Michael's Hospital Community Advisory Panels}

St. Michael's Hospital in Toronto has been engaging members of the inner-city community that the hospital serves through specialized Community Advisory Panels (CAPs) for the last 15 years. These CAPs have a mandate to provide advice to the hospital on priority populations, ensure continuous improvements and advocate on behalf of the populations they represent. Members of the community constitute two thirds of the CAPs and hospital staff make up the other third. The CAPs focus on specific priorities: (1) women and children, (2) the homeless and under-housed and (3) mental health. Chairs of each CAP report directly to the hospital board of directors, and there is a CAP committee of the board that includes members of hospital leadership. The Centre for Research on Inner City Health's evaluation of the CAP program suggested that these partnerships have "been instrumental in generating a broad array of high-visibility, high-impact and patient responsive initiatives for inner city populations" (Centre for Research on Inner City Health, St. Michael's Hospital 2006:1).

The CAPs are an example of a long-standing partnership with the community, which is appropriate in the context of inner-city health, where citizens and interest groups have been enabled by organizations to develop solutions for themselves. The Health Canada (2010) public involvement continuum notes partnering as the highest level of public involvement and influence, where organizations assume an enabling role and agree to implement solutions generated by the public. One example of such an initiative has been the development of patient-responsive facilities, including the Rotary Transition Centre in the Emergency Department. Homeless and under-housed patients can be discharged from the Emergency Department to the centre, a safe, clean and supportive environment in which to recover while transition to the community is arranged (Centre for Research on Inner City Health, St. Michael's Hospital 2006).

\section{Making the Case for Public Engagement in Ontario's Healthcare Organizations}

Longer term, more resource intensive processes of involvement, engagement and partnership may not be an option for all organizations because of cost and human resources constraints. While current research mostly focuses on use of the Web for communication and dissemination to the public, there is a growing interest in using it to facilitate more meaningful, inexpensive and real-time two-way communication (Martin and Ronson 2007). Using the Web can also mitigate some identified barriers to reaching a representative sample of the population through public engagement processes. Personal commitments such as childcare, or professional commitments such as shift work, can preclude much of the population's participation in community engagement (Shields et al. 2010).

In an attempt to overcome vast distances and access difficultto-reach populations, the North West Local Health Integration Network (LHIN) developed a web-based application to lead citizens in the region through a series of exercises to identify priorities for the LHIN Integrated Health Services Plan for 2010-2013. The "Share Your Story, Shape Your Care" exercise first provided the public with an overview of health system issues in the region, reviewed priorities from previous integrated health services plans and requested comments on future priorities (Gallant et al. 2011). Over 800 community members participated. They ranked priority areas for the LHIN, described experiences of coordinated (and uncoordinated) care, provided suggestions for improvement and highlighted priorities that addressed local needs and challenges, many of which were reflected in the Integrated Health Services Plan (Shields et al. 2010).

While many theorists argue for the intrinsic value of public engagement, we are aware that in the current fiscal climate, Ontario's hospitals are motivated to demonstrate return on investments. There are also limitations to public engagement. Formal evaluations of engagement processes are rare, and little high-quality evidence exists to support public engagement in healthcare decision making. This is in part due to the complexities of decision-making processes, which make evidence of the direct impact of public engagement difficult to 
produce (Bruni et al. 2008). In addition, public engagement processes demand significant attention and time from senior leadership and staff; they can be resource intensive.

\section{... public engagement processes demand significant attention and time from senior leadership and staff; they can be resource intensive.}

However, as Ontario attempts to move toward a patientcentred healthcare system, hospitals will no doubt be faced with challenges in ensuring the legitimacy, transparency and validity of important decisions. There are opportunities to leverage the experiences and learn from Ontario hospitals that have engaged their communities in shared decision-making processes.

Experience in Ontario suggests that developing appropriate public engagement approaches can lead to improved quality of healthcare services as well as strengthened relationships with patients, communities and the public - Ontario's most important health system stakeholders. $\mathrm{HQ}$

\section{About the Authors}

Karen Born, MSc, is a member of the Li Ka Shing Knowledge Institute of St. Michael's Hospital and a PhD candidate at the Institute of Health Policy, Management \& Evaluation, University of Toronto.

Andreas Laupacis, MD, MSc, FRCPC, is a member of the Department of Medicine, University of Toronto; the Li Ka Shing Knowledge Institute of St. Michael's Hospital; and the Institute for Clinical Evaluative Sciences.

\section{References}

Abelson, J., P.-G. Forest, J. Eyles, A. Casebeer, E. Martin and G. Mackean. 2007. "Examining the Role of Context in the Implementation of a Deliberative Public Participation Experiment: Results from a Canadian Comparative Study." Social Science \& Medicine 64(10): 2115-28.

Bruni, R., A. Laupacis and D. Martin. 2008. "Public Engagement in Setting Priorities in Health Care." Canadian Medical Association Journal 179(1): 15-18.

Centre for Research on Inner City Health, St. Michael's Hospital. 2006. A Bridge between the Hospital and the People. Community Advisory Panels at St. Michael's Hospital: 2006 Outcomes and Process Evaluation. Retrieved July 11, 2012. <http://www.stmichaelshospital.com/pdf/ crich/caps-evaluation-report.pdf $>$.

Chessie, K. 2009. "Health System Regionalization in Canada's Provincial and Territorial Health Systems: Do Citizen Governance Boards Represent, Engage and Empower?" International Journal of Health Services 39(4): 705-24.

Cole, A. 2011. "Politicians' Role in Reconfiguring Hospitals Should Be Reviewed,' Says King's Fund.” British Medical Journal 34: d5669.

Canadian Institutes of Health Research. 2010. CIHR's Framework for Citizen Engagement. Retrieved July 11, 2012. <http://www.cihr-irsc. gc.ca/e/documents/ce_framework_e.pdf>.
Frankish, C.J., B. Kwan, P.A. Ratner, J. Wharf Higgins and C. Larsen. 2002. "Challenges of Citizen Participation in Regional Health Authorities." Social Sciences \& Medicine 54(10): 1471-80.

Gallant, L.M., C. Irizarry, G. Boone and G.L. Kreps. 2011. “Promoting Participatory Media with Social Media: New Media Applications on Hospital Websites that Enhance Health Education and e-Patients' Voices." Journal of Participatory Medicine 3: e49.

Health Canada. 2000. Health Canada Policy Toolkit for Public Involvement in Decision Making. Corporate Consultation Secretariat, Health Policy and Communications Branch, Health Canada. Retrieved July 10, 2012. <http://www.hc-sc.gc.ca/ahc-asc/alt_formats/pacrbdgapcr/pdf/public-consult/2000decision-eng.pdf>.

Imision, C. 2011. Reconfiguring Hospital Services: Briefing. The Kings Fund. Retrieved July 11, 2012. <http://www.kingsfund.org.uk/ publications/articles/nhs_reconfiguration.html>.

Kingston General Hospital. 2010. KGH 2015: Strategy for Achieving Outstanding Care, Always. Retrieved July 11, 2012. <http://www. $\mathrm{kgh}$. on.ca/en/aboutkgh/strategyandperformance/Documents/KGH_ actionplan_WEB_final.pdf>.

Legislative Assembly of Ontario. 2010. An Act Respecting the Care Provided by Health Care Organizations. Retrieved July 10, 2012. <http://www.ontla.on.ca/bills/bills-files/39_Parliament/Session2/ b046ra.pdf>.

Maioni, A. 2010. "Citizenship and Health Care in Canada." International Journal of Canadian Studies. 42: 225-42.

Martin, N.J. and J. Ronson. 2007. "Opinions: Patient Satisfaction Surveys: Another View." Healthcare Quarterly 10(3): 8. Retrieved July 10, 2012. <http://www.longwoods.com/content/18916 http://www. longwoods.com/content/18916>.

Maxwell, J., S. Rosell and P.-G. Forest. 2003. "Giving Citizens a Voice in Healthcare Policy in Canada. British Medical Journal 326(7397): 1031-3.

Mitton, C., N. Smith, S. Peacock, B. Evoy and J. Abelson. 2009. "Public Participation in Health Care Priority Setting: A Scoping Review." Health Policy 91(3): 219-28.

The Monieson Centre, Queens School of Business. 2010. Northumberland Hills Hospital: Report on the Community Engagement Process. Retrieved July 11, 2012. <http://www.nhh.ca/LinkClick. aspx?fileticket=YOnAbylVzUQ\%3d\&tabid=795\&language=en-US>.

Northumberland Hills Hospital. 2010. Citizens'Advisory Panel on Health Service Prioritization. Retrieved July 11,2012 . <http://www.nhh.ca/LinkClick. aspx?fileticket=jpyxIoXLcDQ\%3d\&tabid=587\&language=en-US>.

Shields, K., G. DuBois-Wing and E. Westwood. 2010. "Share Your Story, Shape Your Care: Engaging the Diverse and Disperse Population of Northwestern Ontario in Healthcare Priority Setting." Healthcare Quarterly 13(3): 86-90. Retrieved July 10, 2012. <http://www. longwoods.com/content/21821>. 